\title{
Impact Factors on Collaboration and Delivery Success in Professional Service B2B Supply Chains
}

\author{
Johanna Bath $^{1} \&$ Ali Öztüren ${ }^{2}$ \\ ${ }^{1}$ Institute of Graduate Studies and Research, Cyprus International University, TRNC, North Cyprus \\ ${ }^{2}$ School of Tourism and Hotel Management, Cyprus International University, TRNC, North Cyprus \\ Correspondence: Johanna Bath, Schwabstr. 2570197 Stuttgart, Germany. Tel: 49-17-9749-5425. E-mail: \\ Johanna.Bath@gmx.de
}

Received: April 27, 2013 Accepted: June 19, 2013 Online Published: August 30, 2013

doi:10.5539/ass.v9n11p201

URL: http://dx.doi.org/10.5539/ass.v9n11p201

\begin{abstract}
Throughout times of market turbulences and even a financial crisis the service sector has established itself as the most important economic sector with a predicted ongoing growth in industrialized countries (Busse \& Wagner, 2008; Leseure, 2010; Bouwman \& De Vos \& Hakker, 2008; Schniering, 2009; Walters 2012). With this there is also a growth in competition within the sector as well as an enlargement and enrichment of customer requirements (Peschl, 2010; Schroedl, 2011; Camarinha \& Afsarmanesh \& Koelmel, 2011). But these requirements are not a one-way-street: interdependencies between customers and service suppliers make relationships within the market of services very complex (Kotler \& Keller, 2008). The study described in this article aims to shed light on these interdependencies that will later define, if a collaboration between a professional service company and its customer is successful and what the measures of success are in terms of evaluating and intangible product. Also these interdependencies will be translated into success factors that both customers and suppliers must apply in order to secure an attractive market position.
\end{abstract}

Keywords: professional service management, service products, supply chain management, collaboration

\section{Introduction}

\subsection{Introduce the Problem}

In a world of globalization, speed-up in development cycles as well as growing multi-level competition for producing companies, outsourcing has been and still is a way to for example stay flexible, gain knowledge or improve quality (Melzer-Ridinger \& Neumann, 2009; Mohr \& Sengupta \& Slater, 2010; Walters, 2012). Outsourcing has been used only in order to save money and to focus the productivity of the own workforce on so called core processes are long gone. Professional service companies that are marked by highly trained professionals and excellent process management know-how as well as the ability to manage challenging face-to-face interaction with customers through the ability to customize their service products have developed (Fitzsimmons \& Fitzsimmons, 2008; Lowendahl, 2009). And there are a use and need for these abilities because customer requirements include solution management through the service supplier (vs. just offering "extended workbenches"). This includes the need to design delivery models that include e.g. a contract form that will allocate financial responsibility for the result of the service delivery on the side of the supplier also, instead of just leasing out employees for a particular job and a particular hourly fee (Peschl, 2010; Schroedl, 2011; Camarinha \& Afsarmanesh \& Koelmel, 2011). Throughout this process professional service companies are being purposefully included in the core processes of producing companies and an interdependence has developed. Not only is the supplier in need for customers and business volumes, but customers do also depend on the know-how, process management, performance and capacity, etc. of their professional service supplier. Through the growing lack of trained professionals, e.g. in the field of engineering or IT, this interdependence is even more prominent. As is generally known from supply chain management in the production supply chain: One partner can only be as good as the other partner within the same supply chain. Mismatches such as opportunistic behavior or the expectation that "plug and play" with new suppliers will just work without proper management will quickly lead to a lack of success within this particular supply chain (Arshinder \& Kanda \& Deshmukh, 2011; Brito \& Nogueira, 2011). 
The aim of this study is to focus a research purely on the narrow field of professional service supply chains (e.g. engineering service suppliers) in order to find out which interdependencies exist between professional service suppliers and their customers. The ultimate goal is to translate these interdependencies into success factors that make or break the success of the collaboration. Also these factors are analyzed in which way they are interrelated as well as which aspect of a successful collaboration they influence. With this information it should be possible to build up a factor model. This model can be applied for further research in order to quantitatively determine the degree of efficiency of each factor as well as their correlation among each other as well as with the success category they aim towards through a confirmatory approach. Within the industry this model can be applied in order to improve the collaboration interface between professional service companies as well as their customers (e.g. sales and buying professionals in the professional service industry as well as professionals that perform or receive services within their daily working processes, e.g. consultants, product engineers, etc.)

The general expectation towards the study was to get a more specific insight from working professionals rather than applying existing scientific rules, e.g. from literature in the field of professional services. Of course general ideas were taken from service management literature but the study was also a green field approach to first of all focus on professional services (rather than on the full spectrum of services) and to give working professionals a voice to explain their day-to-day experiences rather than focus on literature only.

\subsection{Explore Importance of the Problem}

Since the service sector is a relatively new area of research it is - in most books, journals and papers considered as one whole sector. Sometimes there is a distinction between services as a product add-on to a produced good (e.g. telecommunication services, repair services, etc.) but those companies that sell their service as a main product and not as an add-on are usually considered as "one" sector in literature always referred to as the service sector. But now that the market for services in industrialized countries keeps on growing and developing researchers must recognize that there is no such thing as the service sector but that there are different sub-categories of service sectors. Of course the sub-category of professional services in which highly trained professionals perform the service has started to be described in the literature, but due to the difficult accessibility of such professional service individuals not many studies focus on the application of tools and processes at the customer interface. Services will always be intangible and hard to evaluate. Service is and will be people's business and recommendations, word of mouth as well as personal experiences and confidential is of the highest importance (Lowendahl, 2009). This makes it hard to access professional service individuals because they will never voluntarily disclose customer information let alone the difficulties in collaboration or delivery in fear of endangering their reputation. The same is true for service customers: In order to find out about their requirements and needs there is a necessity for customers to know those needs. But many times they cannot clearly put a finger on what they truly expect from a service delivery partner (Lowendahl, 2009). These are influences that make it very hard for outside researchers to truly set foot within this topic. And many studies remain on a level of scientific suggestions rather than an evaluation of the true application of these suggestions and their outcome in real live market conditions. But set aside the significance for research of this study there are also outputs of this study that should be important for the service industry itself or even companies that plan to set a foot into this interesting and attractive industry.

\subsection{Describe Relevant Scholarship}

When the service sector became more and more important in the early 1970s the Havard Business School started research and courses in service operations first by simply applying basic manufacturing concepts to the field of services. Soon researchers recognized the necessity of a trans-disciplinary approach appropriately suited to the unique characteristics of service operation (Heineke \& Davis, 2007; Lowendahl, 2009). Although many approaches in service management are analogous to manufacturing management there are not always parallels between the service products and produced products (Fitzsimmons \& Fitzsimmons, 2008; Schneider \& Bowen, 2010). The key success factors in service management differ widely from the key success factors in the management of producing goods and products (Beyer, 2008). While the economic sectors change, the key success factors of a successful company within this sector change. The significance of success factors of the second sector (e.g. production know-how, product technology know-how) decreases, while the significance of the success factors of the third sector (e.g. solution orientation, individualization) increase which makes a change in the tools and tasks a company uses necessary (Seegy, 2008). Therefore re-searchers, lecturers and textbooks must adapt as well (Lesseure, 2010). And while there are not yet as many text books and studies that are directed solely towards the service sector usually most researchers will at least include one chapter that is purely concerned with services and their special characteristics only. 
Especially operations management has been strongly connected with manufacturing companies, because todays big service companies simply did not yet exist. Only over the last years did operations management develop into an academic discipline that covers both the provision of produced goods and services and the concept shifted from production management to operations management (Leseure, 2010). This study will also make it necessary incorporate a closer look on rather "young" areas of research e.g. the field of business-to-business (B2B) marketing that has been established as an own branch of marketing research in the 1980s and 1990s. This new research era "officially" established services to become one of the important products that could be exchanged between companies and not limiting research in industrial marketing to produced goods only (Ellis, 2011). Same goes to say for the research field of operations management that had its "golden age" also in the 1980s and 1990s when companies were forced to rely on organizational competitiveness rather than on a constant strive for growth. Since the 2000s one of the major fields of interest has become outsourcing that has put it one of the youngest research areas within operations management studies (Reid \& Sanders, 2010). Implementing these research areas to specific collaboration models and their characteristics is taking research even one step further.

\subsection{State Hypotheses and Their Correspondence to Research Design}

Since this study was performed as an exploratory approach through a qualitative study previous hypothesis building did not seem to be the right approach. The topic was more seen as a green-field approach in order to focus not on existing literature but on a very industry application oriented perspective. Rather it focussed on more general questions that can be summarized as follows:

1) Re-check if and how impact factors from the existing literature are applied and as how successful service professionals (as well as their customers) judge these to be? (Through performing and extensive literature research and establishing interviews that will make it possible to question professionals working in the field of services.)

2) Are the service professionals aware of their customers needs and are they able to perform by these customer needs. Or are there other internal or external factors that prevent service suppliers from being able to fulfill their customer's needs?

3) Are service customers aware of their supplier's needs or do they have a negative impact on the supply chain collaboration due to internal or external factors?

4) Is it possible to summarize the customer and supplier needs within one factor model or is there a need to first align the supplier offer with the customer need (and vice versa)?

5) If an alignment of customer and supplier needs/offers is necessary, in which points does this derived from existing literature?

It was expected that there would become clear that there was a derivation between the supplier and the customer view and that this study would lead to the suggestion that an alignment of supplier as well as customer needs and requirements would become necessary. Also it was expected that the application of specific tools that was common would not be considered as valuable as expected and stated in the literature and that certain methods would need to be revised. Therefore the interviews were formulated with a strong focus on the needs and expectations on the one hand as well as offers on the other hand in order to be able to compare those two sides.

\section{Method}

\subsection{Identify Subsections}

In the following the most important subsections of the study will be described. Since the accessibility to the participants was of major importance the sample and sampling procedures will be extensively described. Also the data evaluation will be described since a qualitative study makes it usually necessary to conduct a very detailed analysis of the data usually leading through different perspectives and analysis methods.

\subsection{Participant (Subject) Characteristics}

In order to decide on a sampling procedure it is necessary to first look at the particular challenges the researchers face with the necessary sample for this particular research. As mentioned before the study needs to be applied within a group of highly specialized professionals. Usually these professionals look back on a long career that has let them into a management position. These people can be considered as expert either by the length of time they have worked in a certain field or by the level of insight they have in the field because of the importance of the position they have (e.g. management level). That is why in the qualitative part of the study it is necessary to use the expert sampling method, a non-random selection of individuals that are known experts in the field of interest (Kumar, 2011). On the case of this research the researcher has been working for several years in the field 
of professional services. The researcher worked for two professional service suppliers as well as one professional service customer. Therefore this research is based on a good overview over the branch of professional services. For the sample a small and a large professional service firm was chosen because in the market for professional services the balance between small and large companies is quite equal due e.g. low market entrance barriers that allow a quick entry into the market even for start-ups. This leads to a structure of relatively new (and therefor) small companies as well as big players that have grown in size over the last twenty years. In the study one large professional service company (17.000 employees) as well as a small player (12 employees) were chosen for the interviews. With service customers the structure is more evenly distributed among large manufacturing companies. First of all, large companies are more ready to use professional service partners because of their strategy and their higher budgets. But also large companies are used to hiring service companies and therefor are more professionalized in buying services as well as collaborating with service companies. Therefore we expect better answers in regards to this study from large companies which is the reason for choosing two large manufacturing companies (branches: automotive and transportation) as sampling targets for the qualitative study.

\subsection{Sampling Procedures}

In order to ensure the fulfillment of all stated requirements for a high-quality sample for the qualitative research, there is a list of criteria established that each individual must fulfill before being considered as a possible interviewee. During the interview phase of this qualitative research it was made sure that each interviewee who was later interviewed fulfilled each criterion. Also it was made sure that within each interview each criterion (e.g. privacy) was fulfilled before starting out with the interview. This is very important to ensure the validity of the study. The criterion included only individuals that have worked for a minimum of five years within the professional service industry or as a customer of professional service companies and currently hold a management position in this field.

\subsubsection{Sample Size, Power, and Precision}

At first no sample size was specified in order to react flexible in relation to the received content. In the end ten extended face-to-face interviews were conducted with management professionals. This relatively small number of interviews were due to the fact that the answers to the questions in each group service management professionals and professional service customers were very similar even though the interviewees came from different companies and even branches. In some cases even the wording that was chosen to describe a specific aspect was identical which lead to a very great repetitiveness throughout all interviews. Also it was very important to have an open and confidential discussion in order to get to the core of the challenges. Therefor the interviews were always conducted after meeting with the interviewee beforehand and establishing a trust relationship. Also the interviews were always conducted within a closed room and with only the interviewer present.

The precision of the study can be considered as high since all samples fulfilled the sampling criterion. Besides there was a surprising openness about the struggles, problems and challenges within the professional service collaboration both on the supplier and customer side. This meant that there was little to no hesitation of the interviewees to answer all questions. This includes the questions that directed to more sensible topics like collaborations difficulties. Also surprising was the high degree of consistency between the interviews both on customer and supplier side. The researchers expected there to be differences between the viewpoint of the supplier and customer but there were rarely any differences to be considered.

\subsubsection{Measures and Covariates}

In order to get descriptions and real life examples rather than yes or no answers personal interviews with an open-questioned questionnaire were conducted. In order to design the questionnaire the three-step-method was applied. The first step is characterized by the history of how the participant came into the specific position of interest, the second step is the specific experience of the participant with the situation that is being researched and the third step is the reflection or the meaning of the participant with this specific situation (Seidman, 2006). There was established a different version of the same questionnaire for the supplier and the customer side. The goal of this was to match a customer answer with a supplier answer. For example if one question in the supplier questionnaire asked for a specific offer, the customer was asked for its specific need on this topic (and vice versa). This leads to a compatibility of the customer answer to the supplier answer. The goal was to evaluate if the standpoint of the customer at this particular point was identical with those of the supplier or if the differences could be identified. Due to the confidentiality issues a method like group discussions were not evaluated as fitting. Since it was to be expected that service professionals from different companies would take on a competitive role rather than answering the interview questions truthfully. In order to establish validity and 
reliability before as well as throughout the study and the evaluation a validity and reliability check-list was put in place in order to secure all issues including, confidentiality, establishing trust, taking field notes, interviewee briefing and de-briefing, establishing control mechanisms, etc. One of the most prominent tools of the study was the documentation of the interviews that included extensive field notes in regards to the interview environment, geneal attitude, etc. Also some statements were noted and marked as quotes were the formulation of an answer was particular interesting. Obviously these quotes were marked as stated by the interviewee and set apart from interviewer observations.

\subsubsection{Research Design}

The most important aspect of research design in this qualitative study was to keep the conditions of the interviews as constant as possible. This was of course mandatory for the questionnaire that was used in every interview ensuring that the questions were always asked in the same wording as well as the same order. But it's considered also the environment under which the interviews took place. During the phase of getting to know the interviewees it became clear to the researcher that especially the service professional were often interrupted within the appointment by incoming phone calls, employees as well as other ad hoc interferences. Therefore it became clear to the researcher that interviews should be conducted outside office hours in order to ensure that the focus would remain on the interview. Also the way of scheduling the interviews as well as the introduction to the interview, content and goal of the study were always presented in the same way in order to ensure similar conditions for every interviewee. Eight out of ten interviewees asked deeper questions beyond the general explanation in order to get the full grip on the research scope and the findings that were already gathered. This also shows the interest and the significance on this particular research scope. During the interviews the interviewees were very polite and professional, e.g. the researcher was offered coffee or water, the interviewee had writing material ready in case he or she wanted to take own notes, etc.

\section{Results}

\subsection{Recruitment}

All interviews were conducted between August of 2012 and January of 2013. The time span needed to be large enough in order to find possible appointments with all managers but short enough in order to still ensure similar market conditions under which the interviews took place.

\subsection{Statistics and Data Analysis}

When evaluating the qualitative data a data analytic procedure described in the literature was followed step by step in order to yield reliable results. The first step included transcribing the interview answers as well as the field notes into a structured form. In order to focus on conducting the interview, the notes and answers during the interview were handwritten notes that were later transcribed into computer documents. The result of this was one document that included all data including the field notes per interview. In order to differentiate quotes and statements by the interviewee and field notes or comments by the interviewer the following method was used: During the interview three different categories were marked within the writing. Regular answers were written in plain writing. Special Quotes were marked with "quotation marks". This was used especially for statements that seemed very important to the interviewee or that seemed to transport the message very well. Arrows were used to indicate test that are field notes or notes by the interviewer, e.g. first ideas, thoughts, comments, etc.

When transcribing the interview into computer documents these text marks were transferred as well only substituting the arrows with italic print. As a starting point for the data analysis each interview was therefor available as a print out with three different types of text (regular text, italic print as well as text in quotation marks) in order to differentiate specific categories within the answer. This process of transcribing the interview gives the researcher the chance to carefully go through each interview word by word and re-reading the notes about the own field work as well. Within this process first ideas can be established as well as an outline for the evaluation process can be put forth. While setting up the research and reading the interviews over and over the researcher could gain an idea how to categorize and evaluate the gathered data. Of course these ideas were noted alongside the reading and transcribing process.

As for the categories and themes there are two coding systems that were used. One was the categorizing of the phase of the service process the interviewee mentioned (pre-consumption and consumption/post-consumption) in his answer because after literature research and reading the first interviews it seemed like the interviewees clearly made a difference between having "only" a sale/buy relationship with a supplier or customer or being already working together. This step of the categorizing was done first because this gave the researcher the time to reread the interviews several times and making notes in regards to the content themes that could be discovered. 
Besides this analysis of the process phase the answer of the interviewee was linked with, it was also important to categorize the actual content into themes. Here the major focus was on the influencing factors that were mentioned in regards to the supplier-customer collaboration performance within professional service sales and delivery. These factors needed to be identified and then compared within the group of suppliers and within the group of customers but in a second step also a comparison between the two groups was necessary.

As described before there was the need to use two different coding systems. In order to categorize the phase of the service process that was focused on in the specific answers the text was colored. This was marked by a three color coding system. Plain text would suggest that it was a general statement that could be linked to both service phases (pre-consumption and consumption phase). Yellow text would mark answers with a link to the pre-consumption phase, the pink marked text indicated answers with a link to the consumption/post-consumption phase.

As for the different content themes that indicated influencing factors for the collaboration performance, a system of stickers was developed that could be clued on the text in order to mark the different themes. These content themes were developed with the following method: During the coding process it was suggested in the literature (Ryan, 2006) to make notes with first ideas, interpretations and findings by taking notes alongside the reading and coding process. This was of course done in order to document the process of the development of the interpretation. Especially the process of linking the answers of the suppliers with the answers of the customers as well as categorizing the answers into the process phases the researcher spend a lot of time reading through the data without yet going into the depth of the actual content. Side notes were a very important base that was used later during interpretation. These side notes were accumulated into a mind map that was developed further and further during the interpretation process.

\subsection{Ancillary Analyses}

During the reading process of the data it became clear that the interviews in their current form (each interview in one document and therefore on one print out) would be very hard to evaluate. The questionnaire set up had the goal to get a customer view and a supplier view, but within one print out it was only possible to see one of both views since one interviewee was either a customer or a supplier. Through literature on qualitative interview evaluation (Ryan, 2006) the researcher was encouraged to work with hard copies rather than computer programs. It became clear that cutting out the parts of the interviews that needed direct comparison between the customer and supplier view would make it easier to find similarities and differences. Within this process it was necessary to form categories of questions to be compared. Generally the idea was to get the customer and the supplier view on the same topic on one page. Therefor the questions had to be linked connecting those questions that would give this view by connecting them, e.g. the supplier delivery was matched with the customer expectation in regards to this delivery in order to get a grip on a specific topic from both points of view. In two cases two questions on one side are linked with one question on the other side. Two similar questions in regards to one topic are used for especially important subjects.

\subsection{Baseline Data}

All data gathered throughout the interviews and field notes was included in the data analysis.

\subsubsection{Results from Data Analysis}

Described above the researcher followed three steps of categorizing the data which also lead to a need to describe three different types of data analysis as well as the conclusions drawn from these analyses. The first area of interest was the differences or similarities within the customer-supplier view that was analyzed by creating one answer sheet per supplier answer and linking this answer with its corresponding customer answer on one sheet.

Before the qualitative study was conducted the study was split into two parts - the customer as well as the supplier questionnaire. This was done because there was an expectation that there would be a fair number of questions where there would appear a strong derivation between supplier and customer answers. But already during the interviews it became clear that this would not be the case. Surprisingly in the far majority of the questions the customer and supplier answers were similar or even put into the same words. Apparently only very few details within the supplier-buyer relationship of professional services are not known or considered by the other side. For example when comparing the factors with which a service supplier can differentiate itself from its competitors or what the USPs of a service supplier are, some suppliers stated that even the management gets involved in finding problem solutions. At the same time the customers would state that they expected a high level of commitment and they expected the management level of their suppliers to get involved. Another 
question in which there was a high level of agreement between customer and supplier answers was the question of how to secure mid- and long term collaboration. Here both customers and suppliers ranked aspects like joining processes and standards, open and regular communication as well as joined the planning is very important. One supplier interviewee stated: "It is important to have frequent and regular project status meetings". One customer interviewee answered: "I need to stay in touch with the suppliers through personal meetings and open feedback. This gives the supplier an orientation."

One very interesting feedback was also offered in the last question on the positive effects of an optimized collaboration between suppliers and customers. All interviewees (customer and supplier) stated that there would be a positive effect on their project performance and quality if the collaboration improved. It was also mentioned that there would be lesser risks as well as more efficiency within the project delivery. Through these factors, most of the interviewees stated that this would lead to a higher financial profitability of the professional service projects. This leads to the conclusion that it is important to further specify and clarify the factors that have an influence on the customer-supplier collaboration in professional services.

Only two points were discovered where there was a difference within the answers of the suppliers and customers. One question asked for the marketing and sales tools used. Here the customers are very selective on these tools and methods that help them to form an opinion on what to expect from a specific supplier. One interviewee stated: "In order to evaluate a certain supplier it is important for me to get personal feedback from other customers or colleagues who have worked with this supplier. Of course it is best if I myself have already had experiences with a supplier. Commercial brochures and brightly colored presentations are not valuable for me." This strongly shows what help potential customers to have a tangible impression of a supplier and what does not help. The suppliers on the other hand when asked what marketing and sales tools they implemented most of them stated that they worked with brochures or similar commercial material. This might not be the best way to impress customers and a supplier should not entirely only rely on this method in order to win new customers.

The second topic where there was a derivation between customer and supplier's opinion was the question in which was asked what defines an attractive customer. Here the suppliers often stated that they were looking for customers that had a strong interest in establishing a partnership e.g. through high involvement, aligned strategy development or later even with frame contracts. The customers defined their own attractiveness for suppliers rather through their large size (and therefore the possibility for large turnovers) and other financial aspects like their solvency. In most answers these criteria were mentioned first. Looking deeper into the answers the second answer was usually the image of the customer. This at first seemed pointless since the image does not help the supplier to create a collaborative partnership, but on a second thought the image of a customer will provide the supplier with an important reference for future sales activities. And since references are one of the most important sales and marketing tools the image of a potential customer must be of some value for the supplier.

Besides these two minor points there was no derivation to be found within the interview answers. This leads to the conclusion that the supplier and customer viewpoints in professional services are already quite in line with each other. For the further research this means that it will be a possibility to create one model and therefor one questionnaire for both the supplier and customer answers because they will complement rather than contradict each other. This is a very important finding when it comes to defining the research design of the quantitative study.

The second step of categorizing the data was to evaluate, which phase of the service process (pre-consumption or consumption phase) was of more importance for the interviewees when it came to evaluating the impacts on the overall collaboration performance. When building the collaboration performance model later as a result of the qualitative study this evaluation will be important in order to put an emphasis on one phase or the other or treat both phases as equally important. In order to differentiate between the phases the answers of the interviewees were color coded. The first impression while looking over the colored text was that almost all text was colored. The only little text remained without a color coding. Sometimes this color code showed that there was the use of two colors within one answer which shows that the interviewee differentiated within their answer between the two phases of the service process. This was sometimes done subconsciously by dividing the answer in two logical parts, sometimes it was even done my mentioning it through statements like "During the sales phase I don't have any relationship yet, but when the project starts, I try to [...]". These observations lead to the idea that a clear linkage to the different phases of the service delivery process is possible and should be included in all further consideration.

Also it was easy to gain a quick overview if there was a predominant use of one color. This would mean that within the responses more importance was given to one phase or the other. In our case out of the ten interviews 
conducted six had a predominant use of the pink colored text, which leads to the conclusions that most answered dedicated themselves to the consumption phase. The remaining four interviews were equally covered in pink and yellow which leads to an equal proportion of answers in regards to the pre-consumption as well as consumption phase. When looking closer it turned out that those interviewees that were in their jobs mainly con-cerned with both phases of the delivery process (e.g. sales and project delivery management) ranked the consumption phase as more important. Those interviewees that were in their jobs mainly concerned with the pre-consumption phase (e.g. procurement employees) ranked both phases as equally important. This goes to show that even those employees that are mainly in charge of the pre-consumption phase surprisingly do not rank this phase as most important and some of these employees that are mainly in charge of the pre-consumption phase even rank the consumption phase as more important. Therefore one speculation of this evaluation is that the consumption phase has a slightly higher influence on the overall collaboration performance and project success than the pre-consumption phase. But both phases remain an important part and must be included in a future model and considered within the quantitative research.

The third step of analyzing the data was to form specific themes within the content of the an-swers, marking them by a sticker system. This was done in order to identify the influencing factors for the collaboration performance. In order to be able to find and define those themes, it was necessary to get very involved with the data. This was also done during the first steps of the transcribing of the data as well as the further sorting and categorizing. It quickly became obvious that taking simple notes was not enough to sort the complex themes and interdependencies with-in the service delivery and collaboration. Therefore the instrument of mind mapping was used in order to organize thoughts and ideas and find the underlying structures. During the process of gathering ideas and themes several mind map drafts were put forth even when only the first rough drafts were possible. Below there is the depiction of a very early mind map version that was drafted at the very beginning of the analyzing process, when the data was first read and re-read.

Every time a new mind map was created it was the goal to get a better grip on the full picture and the existing interdependencies within the collaboration. In the beginning the focus was on trying to get the full picture of themes and topics rather than already organizing those topics into categories or minimizing the data. Later when all aspects seemed covered by the mind map, the different topics were trying to summarize to the different themes. The most attention was paid to these questions and answers that contained information on the topic of collaboration performance and delivery quality. In other words how was the perceived collaboration influenced and improved and how did collaboration influence the delivery quality. After reading through the interviews several times it became clear that there were several themes that repeated themselves throughout the different questions as well as the different interviews. One example of these themes is the following statement that was made in regards to the influence on the customer-supplier relationship. One supplier interviewee stated: "I give the customer commitment, my full attention, regular feedback meetings as well as frequent phone and mail contact." Another statement from a customer was: "We conduct strategic supplier meetings. We meet regularly in order to evaluate feedback as well as discuss future collaboration and place new requests with a supplier." It is clear that from these statements the researcher can extract the importance of regular and open communication, feedback as well as commitment and availability on the supplier side in order to be considered for new projects. Another theme throughout the interviews was the following statement: "I need structured processes and procedures while working with my customer." As well as: "We used IT tools in order to integrate the supplier into specific processes and internal routines." Or: "I aim for a process based relationship. I am setting up processes and interfaces in order to have a guideline for collaboration." These and similar statements encourage the researcher to identify the topic "processes" as well as "standards and interfaces" as an important tool within the professional service collaboration. After extracting the most important themes these were identified throughout the text my marking them.

This evaluation of all interviews eventually led to eight different themes that were categorized. Later all statements of the interviewees were then put into one of these categories. This was especially done in order to get defining subcategories and characteristics for these categories since without further explanation they seemed too superficial and vague. The subcategories and characteristics helped to define what was "inside" a specific theme and what suppliers as well as customers stated as important to be included. 
Table 1.

\begin{tabular}{|c|c|}
\hline Category & Subcategory/Characteristics \\
\hline \multirow{3}{*}{ Fairness } & Fair contract negotiation \\
\hline & Aiming for win-win situations \\
\hline & Open and honest handling of errors \\
\hline \multirow{2}{*}{ Commitment } & Involvement of the responsible management level (management commitment) \\
\hline & Take on responsibility \\
\hline \multirow{4}{*}{ Communication } & Regular meetings \\
\hline & Availability of contact person \\
\hline & Clear communication interface ("one face to the customer") \\
\hline & Quick reaction times (especially within bidding process and in case of problems) \\
\hline \multirow{3}{*}{ Processes } & Comply with company guidelines \\
\hline & High quality specification and offer documents \\
\hline & Security through frame contracts \\
\hline \multirow{2}{*}{ Standards/Interfaces } & Clear and transparent buying/sales process \\
\hline & Official project kick-off/information exchange \\
\hline \multirow{4}{*}{$\begin{array}{l}\text { Tangibility/Experienced } \\
\text { competence }\end{array}$} & References \\
\hline & Continuity (e.g. in employees) \\
\hline & Branch Know-How \\
\hline & Method Know-How \\
\hline \multirow{10}{*}{ Collaboration success } & Joined strategy planning \\
\hline & Joined Feedback / lessons learned \\
\hline & Joined past experiences \\
\hline & Re-buy \\
\hline & In line with budget \\
\hline & Successful cash-flow/payment management \\
\hline & Being on time with delivery \\
\hline & Being within the defined quality standards \\
\hline & Added value beyond the original problem \\
\hline & Effective change and error management \\
\hline
\end{tabular}

In these categories there is a complete list that includes the most prominent influencing factors in collaboration and delivery success according to the conducted interviews.

Of course this list does not include any dependencies and interconnections that exist between the individual categories and subcategories and characteristics. The next step within this research will be to provide a model with which this full picture can be shown. A first idea of this can be shown through a structural model that is displayed below. 


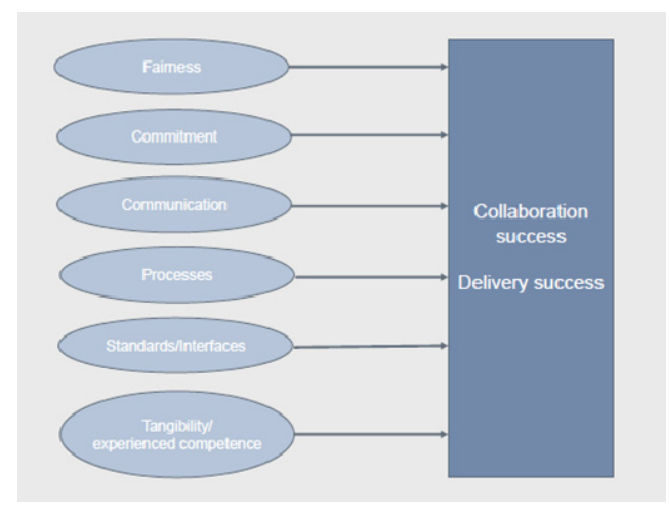

Figure 1. Simple factor model of the impact factors

Of course this model is very simplified and there is not a depiction of existing correlations within each factor as well as with the two success categories of collaboration and delivery success. Also after determining these factors a re-check with literature was done in order to confirm the importance and connection of each subcategory with the main theme.

\section{Discussion}

In general it can be said that the results of this study were quite satisfying in regards to the research problem. The responses of the interview candidates in terms of interest in the study was a very positive feedback. Also the scheduling of the interviews the communication with the interview partner was relatively uncomplicated considering the busy schedules of the managers. During the interviews they very attentive and interested and were eager to understand and answer each question extensively. This was very encouraging in regards to this research project as well as to continue further research.

When it comes to the results one result is especially surprising: Before the study was started the researcher suspected that there would be a difference between the customer needs and the supplier offers as well as the other way around. That is why two of the guideline questions leaded into the direction if there was a mismatch between needs on the one side and offers to fulfill those needs on the other side. But when comparing the questions by topics in regards to matching the needs and offers no such vast differences could be discovered. This lead to an unexpected situation because in the beginning of the research project it was planned to generate two factor models one for the customer side and one for the supplier side and find a way to align the mismatches in offers and expectations/needs. But with this surprising result it was possible to build one factor model for both the supplier as well as the customer side.

The study was very satisfying in regards to the identified factors. Not only was the similarities between the interviews noticeable and the factor analysis therefore relatively clear. Also existing literature did support the factors as important in similar context. But of course a qualitative study does have limitations in regards to evaluating the importance of the identified factors and literature comparison is not always a perfect way because the context and environmental conditions may differ too much so that it is not possible to draw a direct comparison. Therefore it is absolutely necessary to conduct a quantitative confirmatory study in order to confirm the identified factors and evaluate their importance. In this study it is also necessary to have a full coverage of reliability for the professional service market which leads to the necessity of a large amount of samples.

The validity and reliability of the study can be considered as satisfying, the largest cause of possible limitations must be considered the rather small sample size. Even though four companies were included the sample size leaves open questions in regards to the transferability of the data within these companies as well as with other companies outside of the sampling scope. Again it is strongly suggested that a countrywide professional service studio with a confirmative approach is conducted in order to strongly confirm the factors. But in order to gain a first knowledge of what is important on the collaboration interface between professional service suppliers and their customers this study does give a good first indication of what is important and what a working professional should focus on when working on this interface.

\section{References}

Arshinder, K., Kanda, A., \& Deshmukh, S. G. (2011). A Review on Supply Chain Coordination. In T. M. Choi, \& 
T. C. E. Cheng (Eds.), Supply Chain Coordination under Uncertainty (pp. 41-43). Hongkong: Springer.

Beyer, M. (2008). Strategische Entwicklung des Servicegeschäfts in Industrieunternehmen. In R. Gleich, W. Friedrich, U. Seegy, \& M. Tilebein (Eds.), Dienstleistungsmanagement in der Investitionsgüterindustrie (pp. 27). Frankfurt: Peter Lang Verlag.

Blomquist, K. (2002). Partnering in the dynamic environment. In The role of trust in antisymetric technology partnership formation (pp. 35-38). Thesis for Doctor of Science, University of Lappeenranta, Finland.

Blomquist, K., \& Levy, J. (2006). Collaboration capability-a focal concept in knowledge creation and innovation collaboration in networks. Internation Journal Management Concepts and Philosophy, 2(1), 39-40.

Bouwman, H., \& Fielt, E. (2008). Service Innovation and Business Models. In H. Bouwman, H. De Vos, \& T. Haaker (Eds.), Mobile Service Innovation and Business Models (pp. 9-17). Berlin: LIT Verlag. http://dx.doi.org/10.1007/978-3-540-79238-3_1

Brito, C., \& Nogueira, M. (2011). Managing IT Suppliers: a capability-based Approach. In T. M. Choi, \& T. C. E. Cheng, (Eds.), Supply Chain Coordination under Uncertainty (pp. 602-603). Hong Kong: Springer.

Bruce, M., Leverick, F., \& Little, D. (1995). Complexities of collaborative product development. Journal Technovation, 15(9), 537.

Busse, C., \& Wagner, S. (2008). Managing Innovation. Berne: Haufe.

Camarinha-Matos, L., Afsarmanesh, H., \& Koelmel, B. (2011). Collaborative Networks in Support of service-enhanced Products. Heidelberg: Springer.

Corswant, F., \& von Tunaelv, C. (2002). Coordinating customer and proactive suppliers, A case study of supplier cooperation in product development. Journal of Engineering and Technology Management, 256-258.

Ellis, N. (2011). Business-to-Business Marketing, Relationships, Networks \& Structures. New York: Gabler.

Fitzsimmons, J. A., \& Fitzsimmons, M. (2008). Service management: Operations, Strategy, Information Technology (6th ed.). New York: Oxford University Press.

Gunter, H., De Snoo, C., Shepherd, C., \& Moscoso, P. (2011). Collaborative Planning in Supply Chains: The Importance of Creatign High Quality Relationship in the Value Chain in Behavioral Operations in Planning and Scheduling. New York: Springer.

Heide, J., \& John, G. (1992). Do norms matter in marketing relationships? Journal of Marketing, 56, 41-42. http://dx.doi.org/10.2307/1252040

Heimeriks, K. (2002). Alliance Capability, Collaboration Quality and Alliance Performance: An integrated Framework. Eindhoven - Center of Innovation Studies, 9.

Heineke, J., \& Davis, M. (2007). The Emergence of Service Operations Management as an Academic Discipline. Journal of Operations Management, 25(2), 364. http://dx.doi.org/10.1016/j.jom.2006.11.003

Kotler, P., \& Keller, K. (2009). A Framework for Marketing Management (4th ed.). Upper Saddle River: Pearson Education.

Kumar, R. (2011). Research Methodology (3rd ed.). London: Sage.

Leseure, M. (2010). Key Concepts in Operations Management. London: Springer.

Lindlof, T., \& Taylor, B. (2011). Qualitative Communication Research Methods (3rd ed.). London, Sage.

Lowendahl, B. R. (2009). Professional Service Firms (3rd ed.). Copenhagen: Oxford University Press.

Masterson, R., \& Pickton, D. (2010). Marketing an introduction (2nd ed.). London: Sage.

Melzer-Ridiner, R., \& Neumann, A. (2009). Dienstleistung und Produktion (1st ed.), Heidelberg: Gabler.

Merriam, S. (2009). Qualitative Research, A guide to design and implementation. San Fransisco: John Wiley \& Sons.

Merrill-Sands, D., \& Sheridan, B. (1996). Developing and Managing collaborative alliances, Lessons from a review of literature. Organizational Change Briefing Note, (3), 8.

Mohr, J., Sengupta, S., \& Slater, S. (2010). Marketing of High-Technology products and innovations. Upper Saddle River: World Scinetific Publishing.

Morgan, R., \& Hunt, S. (1994). The commitment-trust theory of relationship marketing. Journal of Marketing. http://dx.doi.org/10.2307/1252308 
$\mathrm{Ng}$, I. C. L. (2009). The pricing and revenue management of services. New York: Routledge.

Peschl, T. (2010). Strategisches Management hybrider Leistungsbündel. Stuttgart: Gabler.

Peters, B. (2008). Innovation and Firm Performance. Heidelberg, New York: Sage.

Ragatz, G., Handfield, R., \& Petersen, K. (2002). Bennefits associated with supplier integration into new product development under conditions of technology uncertainty. Journal of Business Research, (55), 390-391.

Reid, D., \& Sanders, N. (2010). Operations Management an integrated approach. Hoboken: Oxford University Press.

Rieck, A. (2011). Qualitätsprüfung komplexer Dienstleistung. Wiesbaden: Physica. http://dx.doi.org/10.1007/978-3-8349-6322-2

Ryan, A. B. (2006). Methodology: Analysing Qualitative Data and Writing up your Findings. In M. Antonesa, H. Fallon, A. B. Ryan, A. Ryan, T. Walsh, \& L. Borys (Eds.), Researching and Writing your Thesis. A Guide for postgraduate students (pp. 98-99). Maynooth: Mace.

Schneider, B., \& Bowen, D. (2019). Winning the service game. Havard Business School Press, 1.

Schniering, N. (2009). Industrielle Dienstleistungsinnovation. Berlin: Haufe.

Schroedl, H. (2010). Towards a Model for Strategic Supply Network Development for value bundles in Pioneering Solutions in Supply Chain Management. Berlin: Erich Schmidt Verlag.

Seegy, U. (2008). Dienstleistungskompetenz im Maschinen- und Anlagenbau. In R. Gleich, W. Friedrich, U. Seegy, \& M. Tilebein (Eds.), Dienstleistungsmanagement in der Investitionsgüterindustrie (pp. 38). Frankfurt: Peter Lang Verlag.

Seidman, I. (2006). Interviewing as qualitative research (3rd ed.). New York: Teachers College Press.

Walters, D. (2012). Competition, Collaboration and Creating Value in the Value Chain. In Jodlbauer, Olhager, Schonberger (Eds.), Modelling Value (pp. 3, 4, 22). Washington: Physica.

West, D., Ford, J., \& Ibrahim, E. (2010). Strategic Marketing (2nd ed.). Oxford: Pearson.

Woo, K., \& Ennew, C. (2004). Business-to-Business relationship quality. In European Journal of Marketing, $38(9), 1255-1259$.

\section{Copyrights}

Copyright for this article is retained by the author(s), with first publication rights granted to the journal.

This is an open-access article distributed under the terms and conditions of the Creative Commons Attribution license (http://creativecommons.org/licenses/by/3.0/). 